\title{
Navigating and decoding dynamic maps: Gender preferences and engagement differences within- and outside-of game experiences
}

\author{
Tom Lowrie \\ Charles Sturt University, Australia \\ Robyn Jorgensen \\ Griffith University, Australia \\ Tracy Logan \\ Charles Sturt University, Australia
}

\begin{abstract}
A survey $(n=410)$ revealed statistically significant gender differences between middle school students' preference for playing particular types of games. Subsequent instrumental case studies theorised the "within-game" and "out-of-game" experiences of two middle school students as they played a digital hand-held game. These two case studies comprised stimulated recall sessions and subsequent follow-up, open-ended interviews. The analysis described the influence digital game playing can have on a participant's mathematics sense making. Findings included distinct differences in both the approach and the strategies employed by the respective participants to not only engage with the game, but contextualise it within their own knowledge and experiences. Furthermore, the study demonstrated the extent to which game playing can be a catalyst for further learning outside the game experience.
\end{abstract}

\section{Introduction}

A substantial, and ongoing, body of research literature has identified gender differences with respect to students' navigation and mapping skills (e.g., Lawton \& Kallai, 2002; Sandstrom, Kaufman, \& Huettel, 1998; Thorndyke, 1982). Typically, participants in these studies are undergraduate students, and the performance differences in favour of males are evident on most navigational tasks (Wolbers \& Hegarty, 2010). Kitchin (1996) argued that these differences were likely to be a result of the fact that females have less access to situations that develop spatial skills or that navigational tasks favour male problem-solving strategies. Interestingly, Boardman (1990) highlighted the fact that gender difference in mapping ability tended to increase over time and that by adolescence boys demonstrated more highly developed map skills than girls.

Lawton and Kallai (2002) reported that males and females tend to use different wayfinding strategieswith men typically using strategies which ensure they orientate toward global reference points while women have a preference for using strategies based on route information. Thus, males tend to express their position in relation to compass points and directions by "maintaining a sense of their own position in relation to environmental reference points" (Lawton, 1994; p. 765). By contrast, females tend to focus on particular landmarks and are less likely to position themselves within the navigational space-instead focusing on instructions on how to get from place to place. In commenting on significant performance differences in favour of males on wayfinding tasks, Lawton and Kallai (2002) proposed that from a young age males were more likely to engage with wayfinding experiences while females felt "less safe" navigating space and therefore less likely to establish such independent experiences. In an age where young children are less likely to "be allowed" to be adventurous and explore their environment-in part due to heightened safety concerns and a somewhat more protective society-it could be argued that both males and females have less exposure to wayfinding experiences at an early age.

Kimchi, Amishav, and Sulitzeanu-Kenan (2009) suggested that women and men differ in their ability to use cognitive schemes to judge whether spatial information is of relevance or not. Females tend to consider most information presented to them whilst males are more successful at deciphering essential information. Consequently, it is both the nature of the task and the visual context within which the task is embedded which result in gender differences. In an information age, where maps are becoming more detailed, complex (in terms of information contained in the map) and dynamic (Lowrie \& Diezmann, 
2009 ) it is increasingly important that all students possess appropriate strategies to decode maps. Moreover, it appears that the development of appropriate strategies needs to start at an early age. Diezmann and Lowrie (2008) found consistent performance differences in favour of males on mathematics assessment tasks that contained a map graphic. Their longitudinal studies (see Lowrie \& Diezmann, 2011; Lowrie \& Diezmann, 2007) found significant differences through elementary and middle schooling (ages 8 to 12 year olds) on a variety of map tasks that included coordinate grids, pictorial maps and street directory representations. In their studies, these differences were present even when spatial ability was controlled for.

Students' initial exposure to maps are likely to be through computer games and other digital gaming devices - and these experiences may well be before school or in out-of-school contexts. Since gender differences are typically more pronounced when tested in simulated environments (Hegarty, Montello, Richardson, Ishikawa, \& Lovelace, 2006), this study examines students decoding map information in digital environments. To date, it is difficult to determine whether these performance differences are a result of strategy use or an effective use of similar strategies (Saucier et al., 2002). This investigation seeks to determine whether there are differences in the approaches taken by middle school-aged students to play map-based games and determine the type of strategies (effective or not) students employ when navigating through map space.

\section{Relevant literature and context}

This study investigates the type of games middle school students like to play and examines the strategies and approaches they utilised in game playing situations - with a specific focus on gender - and especially focuses on the manner in which games become embedded within the social fabric of learning. The foundation of the study is based on the premise that digital games promote certain types of navigation and wayfinding - and that from an early age students' visual reason is influenced by exposure to, and engagement with, such technologies. To date, most studies that have investigated the nature and effect of technology on students' visual reasoning predominately focus on the actual technology (or device) rather than its contextual and social impact. As de Kort, Ijsselsteijn, and Gajadhar (2007) argued, "the rich interactive experiences associated with digital games can only be fully understood when the 'system' is conceptualised as more than the software and hardware" (p. 5). Since it is widely recognised that electronic games and e-mediated learning give rise to engaging and meaningful social interactions (Buckingham, 2007; Gee, 2007), it is the impact digital games have on contextualised learning that is worthy of further investigation.

Until recently, there has been an obvious divide between so called educational- and entertainment-based software (and games). Most educational software has been restricted to drill-and-practice frameworks which conduct the repetitive reinforcement of basic facts and skills (Charsky, 2010; Rice, 2007; Van Eck, 2006). Although many of these software titles are now visually appealing, their foundations predominantly remain the same. The only educational developments in these games over the past 20 years would be the potential for increased motivational and intrinsic rewards. By contrast, entertainment games tend to have more scope, flexibility and opportunities for decision making, allowing "problems to be solved in multiple ways" (Gee, 2007; p. 216). This contrast is also evident in classroom contexts. Many programs associated with school mathematics are constructed within drill-and-practice architectures, and thus the same "divide" exists in school contexts - despite evidence that suggests the greater utility of almost every other type of genre (Wenglinsky, 1998). Nevertheless, distinctions between these genres have become somewhat blurred as Buckingham (2007) suggests:

the emergence of 'edutainment', a hybrid mix of education and entertainment that relies heavily on visual material, on narrative or game-like formats, and on more informal, less didactic styles of address. At least on the face of it, this material embodies a form of 'popular' pedagogy that is much less authoritarian — and much more 'interactive' - than that of formal schooling (pp. 123-124).

Thus, games offer a form of out-of-school learning seldom afforded to school-based learning — and a form of learning that promotes wayfinding and navigational skills. In fact, within today's crowded curriculum (Wien \& Darling-Hammond, 1998), it seems likely that the learning and engagement that takes place through gaming will not be afforded any time or place in schools. 
There is conflicting research in terms of the influence digital technologies have on students' learning. Some studies have shown little transferability between the skills and understandings developed in game contexts and that of school curricula (e.g., Henderson, Klemes, \& Eshet, 2000; Sandford, Ulicsak, Facer, \& Rudd, 2006; Shin, Norris, \& Soloway, 2006) and this is the case even when considering specific spatial expertise (Feng, Spence, \& Pratt, 2007; Sims \& Mayer, 2002). However, other studies have demonstrated that broad positive learning outcomes are established through game play. Such experiences seem to improve general problem-solving skills (Amory, Naicker, Vincent, \& Adams, 1999; Betz, 1996; Miller \& Robertson, 2010) and creative thinking (Rieber, Smith, \& Noah, 1998) while providing the opportunity for users to evoke and utilise external images within and outside the game playing environment (Nemirovsky \& Noble, 1997). In fact, some research suggests that simulation-based games are one of the most powerful ways of encouraging young children to construct meaningful links between threedimensional and two-dimensional objects since many school-based conceptual understandings are considered in isolation (Lowrie, 2002).

\section{Focus of the study}

This investigation goes beyond studies that attempt to determine links between game playing and the development of particular skills and understandings - and certainly beyond links between in-school and out-of-school learning. Rather, this study considers the utility of gaming and the degree to which games provide a catalyst for enhanced learning opportunities. Specifically, the study aims to:

1. Determine middle school students' "representational" gaming preference;

2. Establish how game players navigate digital worlds and process information; and

3. Explore the notion of game playing as a catalyst for extended learning opportunities.

\section{Method}

A two-phase, sequential multi-method approach was utilised to address the research questions. A twophase approach provided the opportunity for the first phase to inform the second phase, where this provided a logical extension from the previous findings (Morse, 2003). The first phase comprised a survey that sought to identify students' game playing habits and specifically the types of games they played which included mathematics content and/or required mathematics reasoning. The second phase detailed the game playing habits of two case study participants who could be considered instrumental cases of the survey findings.

Thus, the first phase identified patterns, relationships and differences among a large cohort of game players while the second phase was exemplary in nature-and consequently provided more detailed insights into patterns that emerged from the larger sample (Morse, 2003).

\section{The survey design and analysis of data}

The survey was designed to describe the nature of student use of a range of entertainment-based digital games with specific reference to mathematics content. The participants comprised 410 students $(\mathrm{M}=195$; $\mathrm{F}=215$ ) from two geographically-distinct locations (Metropolitan=171 and Non-Metropolitan=239) in Australia. The participants were aged $10-12$ years (mean age $=10.8$ years).

The survey sought information that would provide patterns of student behaviour in relation to preference for the content and processes involved in playing the games. The survey used in this study was based on the British Educational Technologies and Communications Agency (BECTA) (2002) questionnaire on Young People's Use of ICT and adapted specifically for this study. Further information regarding survey validity is described elsewhere (see Lowrie \& Jorgensen, 2011). One component of the survey required participants to describe the type of mathematics content they encountered when playing digital games in out-of-school situations. These categories were classified as number content, map content, graph content and problem solving processes.

ANOVA's revealed statistically significant differences in game playing preference of males and females in two of the four variables; namely, on map content $[F(1,410=24.13, p<.001]$ and problem solving processes $[F(1,410=17.78, p<.001]$ variables. Males $(M=2.98)$ were more likely to play games containing 
map content than females $(M=2.32)$. By contrast, females $(M=2.56)$ were more likely to play games involving problem solving than males $(M=1.98)$.

The gender differences identify the type of mathematics content that males and females prefer to engage with. One explanation for males' preference for digital games that contain maps could be associated with the general assumption that they prefer games that are graphically sophisticated and often involve competitive traits (Hartmann \& Klimmt, 2006; Zevenbergen, 2007). Other studies (e.g., Lowrie \& Diezmann, 2011; Lowrie \& Diezmann, 2007) have shown that boys outperform girls on mathematics items that require the decoding of spatial information-and particularly tasks that required the interpretation of map-based graphics. By contrast, females prefer playing games that required problem solving and scaffolded challenges that involve logic (Lucas \& Sherry, 2004; Quaiser-Pohl, Geiser, \& Lehmann, 2006).

The second component of our study detailed the game playing habits of two case study participants-one male and one female - in order to describe the different approaches and perspectives they bring to a game context. It is this aspect of the larger study that is the focus of the remainder of the paper.

\section{Instrumental case studies}

This inquiry used an instrumental case study design (Stake, 1995) which is a technique that can be used to advance the understanding of patterns that have emerged from research findings. In this case, two participants were chosen because they were able to give the researchers access to the discursive practices of the game playing environments and to illuminate the extent to which they engaged with the gameplaying context. Furthermore, the two participants were instrumental cases for providing depth to the analyses of survey data - that is, the results that revealed distinct game-playing preferences of boys and girls. Through using such a case study analysis, the researchers were able to theorise the "within-game" and "out-of-game" experiences the participants accessed and employed as part of their personal game playing. These two case studies comprised stimulated recall sessions and subsequent follow-up, openended interviews. The data from the case studies provided illustrative cases of how the two players navigated their way through the game structures. These cases are drawn upon to help explain/theorise the gender differences noted in the survey responses. These two cases are not meant to provide evidence of gender differences per se but serve to highlight the strategies employed by the two players - thus they are illustrative and illuminative in terms of gendered processes.

Stimulated recall is an "...introspective method that can be used to elicit people's thought processes and strategies when carrying out an activity or task" (Henderson \& Tallman, 2006; p. 55) and utilises a support mechanism to enhance recall (Gass \& Mackey, 2000; Henderson \& Tallman, 2006). In this study, case study participants were given a Nintendo DS and The Legend of Zelda: Phantom Hourglass game (Nintendo, 2008) and were asked to play the game as much as possible over a two-week period. The participants were then videotaped, for approximately 30 minutes, at the natural progression in the game. Thus, the game-playing episode was at a novel point that was new to the participants. Two camera angles were utilised, one focused on the two screens of the Nintendo DS and the other was a front view of the participant. These two video files were edited using Studiocode software (Studiocode Business Group, 2003) to create video footage that presented both the screen view and the front view simultaneously. Semi-structured interviews were conducted with the participants after the game playing episode to elicit their reactions to the experience and to encourage the participants to describe their game playing patterns over the duration of the activity.

Within a week, the participants undertook a stimulated recall session that involved them watching the video footage of their game playing episode and answering a predesigned set of semi-structured and open-ended questions based on particular points and moments in the game that were significant (as identified by an expert who had previously played the game and identified significant signposts at each level (see Jorgensen \& Lowrie, 2011). Participants also had the opportunity to pause the tape at any time to discuss what they were thinking. As Morgan (2007) points out, the stimulated recall session is a metacognitive activity that requires students to consciously reflect on their own thinking processes. These stimulated recall sessions were also videotaped for subsequent analysis. 


\section{Case study participants}

The two case study participants were selected through an expression of interest that sought to identify middle school students' willingness to play specific hand-held games and be prepared to participate in the three-week study. Criteria for participation included a gender balance, students of varying game playing expertise, and between the ages of 11-14 years. The boy, Steve, was in Grade 6 of primary school (aged 11) and was experienced with such game playing contexts; while the girl, Claire, was in Grade 8 of secondary school (aged 14) and seldom played these types of games.

\section{The case study game}

The game selected for case study analysis was The Legend of Zelda: Phantom Hourglass (Nintendo, 2008), a game belonging to the adventure genre. This genre is based around a problem-solving environment where "players are placed in scenarios in which they must synthesize diverse information and analyse strategies. Within the adventure game genre, narrative provides two main functions: both motivation and a cognitive framework for problem solving" (Dickey, 2006; pp. 250-251).

The game was selected for a number of reasons, namely it: (a) was a game used on hand-held consoles and therefore could be played in various contexts and settings; (b) required high levels of spatial processing (e.g., mapping); and (c) facilitated curriculum-based mathematics ideas (e.g., problem solving, two-and-three dimensional space, and position). This particular adventure game provided a common platform for case study investigation since it had: (a) high levels of visual and graphics representation; and (b) high textual and literacy demands. Consequently, the game provided opportunities for the instrumental nature of the study design to be promoted. Similarly, it was important to ensure the game had sufficient mathematics and numeracy demands since the survey questions and subsequent confirmatory patterns of analysis were embedded within a mathematics context.

The Nintendo DS two-screen structure also lent itself to various levels of spatial processing. For example, the top screen of the Nintendo DS is almost always represented from a top-down view (bird's-eye perspective) while the bottom screen positions the game play from a $45^{\circ}$ front-view perspective. The top screen of the DS provides a map of where you (i.e., the player) currently are, and all actual playing occurs on the bottom screen using the stylus. The position of the player is always shown on the map. Using the stylus, players are able to make notes on the map (see Figure 1), chart routes for their boat (see Figure 2), or draw paths for their various weapons.

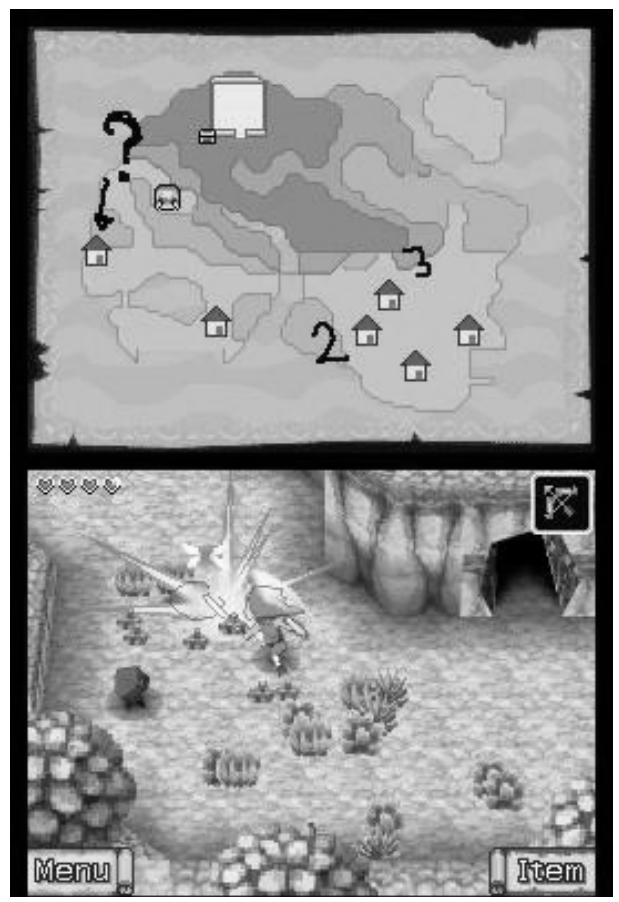

Figure 1. Screen shot of two screens showing player's notes on a map. 


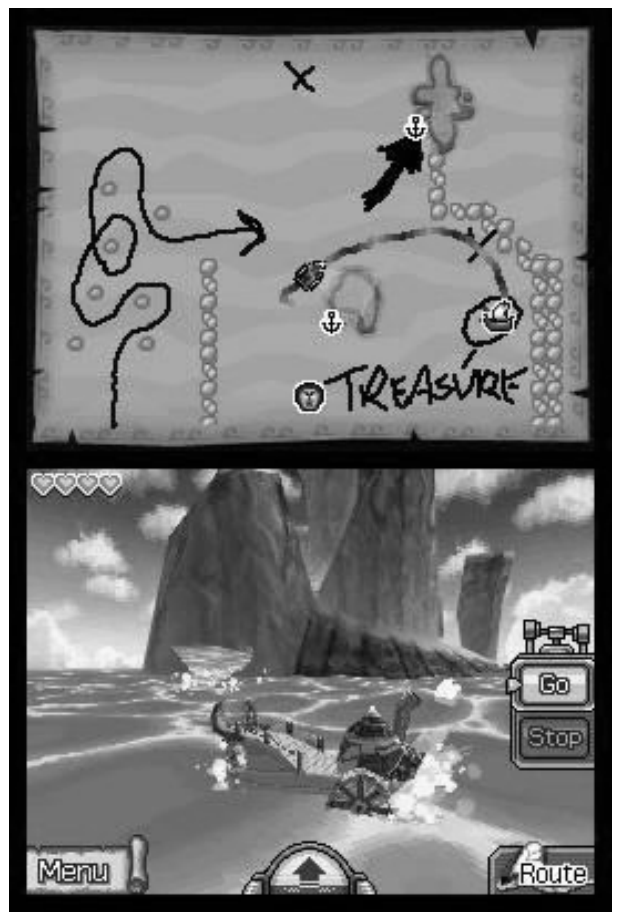

Figure 2. Screen shot of two screens showing player's boat route and notes on the map.

This game challenged the player to navigate around various terrains in order to locate a lost person.

The game follows the adventures of Link and Tetra, the leader of a band of pirates, as they discover a ghost ship in dense fog. Link falls into the ocean when Tetra gets into trouble, and he wakes up alone on the shore of a mysterious island. Throughout the game, Link collects sand for his Phantom Hourglass, which allows him to explore deeper and deeper into a time-limited dungeon in his quest to find Tetra (retrieved from http://ds.ign.com/objects/694/694756.html)

Like many adventure games, much of the game play had scaffolded tasks that had to be completed before moving to the next phase of the game. The player is required to interpret maps represented from different perspectives and orientations, locate landmarks, estimate distances and remember locations.

\section{The case study context}

The instrumental case study design was especially appropriate for this study since the case itself is secondary to understanding a particular phenomenon (Stake, 1995). That is, the cases are designed around the results of the first phase of the project. To this end, we acknowledge that the selection of participants is not comparative between the cases, in fact, that is the intention. The cases are within patterns that emerged from the quantitative aspects of the study. Consequently, we acknowledge that the boy in the study was an experienced adventure game player while the girl was a novice with respect to these types of games. The girl was highly articulate with an extensive vocabulary, whereas the boy possessed high levels of visual imagery and spatial ability. These profile features are consistent with previous findings (e.g., Hegarty et al., 2006; Lowrie, 2002; Lowrie \& Diezmann, 2011) and the results described in Phase 1 of the current investigation.

\section{Results and discussion}

The case studies sought to describe patterns of behaviour that were observed in authentic settings in order to better understand patterns that emerged from the quantitative component of the study. Thus, the instrumental case studies sought to analyse the approaches and specific strategies students employed to 
complete activities within the game context and describe learning pathways that arose from game playing - through rich, contextualised, descriptions of patterns of behaviour.

\section{Navigating the game space}

The two case study participants used quite different strategies to navigate the game space. Steve was quite proficient at moving around and within the spatial dimensions of the game environment and could simultaneously interpret and decode information on both screens. Moreover, he utilised the dual-coded features of the game to great effect. For example, he frequently translated screen representations so that he could utilise the drawing facility from the top screen of the game console to help navigate and monitor his journey.

\begin{tabular}{|c|c|}
\hline Steve: & $\begin{array}{l}\text { So then we've got to find the key, the door with the key. You can find it if } \\
\text { you look at the map on the top screen. }\end{array}$ \\
\hline Interviewer: & So how much do you use the top screen? \\
\hline Steve: & $\begin{array}{l}\text { I use it a lot because it tells you where the phantoms are and it shows you } \\
\text { where the treasure chests are and you can write things on the map to make } \\
\text { memories of different things. }\end{array}$ \\
\hline Interviewer: & So you couldn't play the game without the top screen? \\
\hline Steve: & $\begin{array}{l}\text { No, not at all. It really, the map's one of the most important things of the } \\
\text { game. }\end{array}$ \\
\hline Interviewer: & Do the maps change a lot or is it the same structure? \\
\hline Steve: & $\begin{array}{l}\text { Well sort of, each different place you're in has a different environment to } \\
\text { explore so most of the maps are pretty different. The ones I played on } \\
\text { weren't the same. }\end{array}$ \\
\hline
\end{tabular}

The dual screen approach embedded within the console's functionality was utilised to great effect. As Steve explained:

Steve:
phe screens are really the most helpful when you're in levels with
you look at the screen you can often see a pattern in where they're
looking. Um, the screen also shows you where spikes are and doors are so
if you find a key that you don't know where the door is you can look at
the screen to try and find, the top screen, to try and find where the door is
and also it tells you if any doors have opened or any spikes have gone
down or anything, on the top screen too.
Ok, so is the top screen always an exact replication of the bottom and
vice-versa or is sometimes that you might have different information on
one than the other?
I think most of the time it's an exact map of the bottom screen. There was
one island I went to where it was an uncharted island so you had to make
a map of it for yourself...See if you press the one of the arrow keys the
map goes down to the bottom screen so you can make memories on the
map.

The game environment generally required the game player to process spatial concepts from different perspectives and across different representations. In a typical classroom situation, opportunities for such cognitive processing are limited and are certainly not dynamic. At school, the development of these skills is often framed within activities that require the identification (location) of fixed and static points (e.g., coordinate grids, maps with fixed compass bearings). Furthermore, relationships between 2D and 3D representations rarely move beyond simple representations (e.g., identifying how many squares are in a cube). In the gaming situation, Steve used the game's tools to create markers to aid his progress through the game and thus used dynamic imagery (Presmeg, 1986) to go beyond static (and context-free) representations.

Claire's utilisation of information from both screens was limited and when she did access both screens she tended to use the information independently. Thus, she did not integrate features of the dual screen to 
navigate through space - and rarely used the drawing tool to create her own maps to scaffold her ideas or plan her navigation.

Claire typically navigated the screen space in a deliberate manner-and tended not to use trial-and-error strategies as much as Steve. As Claire explained:

...like tried to figure out maybe if I do this it will work and then in the end it was like it kind of became the answer was in front of my nose the whole time but I kept complicating it to try and...I would overcomplicate the plan when it was really just a simple thing. I suppose you do that in real life, you sit down and you go, maybe if I do this and then do this it will work out when really it's like a one-step problem. So it was kind of like the game in a way.

It was noticeable how purposeful Claire was when using the DS stylus. Her screen movements were carefully planned - she did not explore the game space without conscious intent. In addition, Claire was more considered in her decision making due to the fact that she processed all of the written information thoroughly and considered it to be all relevant and important.

Interviewer: What about just throughout the game in general, like, the written information?

Claire: When I first started playing there was a lot of written information (which is generally what happens at the start of most games)...it was helpful, like, it explained that I had to go and find a weapon so I could play the game. And then it explained how I used it and just when you go and talk to people, they tell you their little speech bubble comes up and yeah it's important. Most of the written information in this game is quite important. There's not just a lot of pointless talking, like in some other games. You kind of have to, read all the information to understand what's going on for some bits.

By contrast, Steve's screen movements were hurried and seemingly erratic. His game play rapidness meant that he was required to make many more decisions than Claire because he only skim read the written information - "Well, I was just kind of skim reading them a bit". Steve's decision making was most influenced by the graphic components of the game, while Claire was more influenced by the written text.

The reliance on the text and its influence on decision making became more apparent for Claire as the game became more challenging.

Interviewer: So would you say there's anything different about the information you're given there, compared to earlier in the game?

Claire: $\quad$ Earlier in the game, towards the start it was more so explaining how to move around and how to use your weapons and stuff 'cause you're new to the game. But towards this part of the game, it was more so about finding the spirits and it was getting more into depth about the game, but at the start it was just [the] basics. And now the information, it becomes more important as the game goes on. I figured out like some skills that I learnt were that you had to read everything like properly to understand.

While Claire was careful and deliberate in her intentions, Steve remained just as successful despite the fact his approach appeared scattered. He made decisions and solved problems with precision and strategic focus as he was able to describe the strategies he was about to employ. Thus, his apparent trial-and-error approach contained higher-order thinking processes - he was reflective, self-monitoring and formulated what-if scenarios. 
Steve: $\quad$ Now I've been to this island before and there was a challenge there that I just wrote it down on the top screen because it's an uncharted island but I didn't actually solve it. I thought maybe I'd come back later. So maybe I thought there was something that I didn't collect here.

Steve: Well, I'd already been through part of this section before when I went to another island to get the bomb bag thing so I could throw bombs and when I was there before I noticed that there was some cracks in the wall and if there's cracks in the wall that means you can throw a bomb there and it will explode so then it's a shorter way to get through. But I hadn't got that key before and I try to, I step on the thing and then the spikes went down but then when I walked off it to go and get the key, the spikes went back up and I hurt the character a bit. So, then I tried again but it didn't work and lots of the game is trying to use your items wisely, so I thought the boomerang might be able to pick up things so I used the boomerang and because you can use the boomerang to flip switches you might be able to use the boomerang to bring things back to you because you can use the boomerang to bring money back to you if you see it over a chasm or something. So I thought maybe you'd be able to collect the key with it and it worked.

Steve's "learning by doing" approach (Anzai \& Simon, 1979; Garris, Ahlers, \& Driskell, 2002) was based around risk taking, high levels of confidence and an obvious capacity to effectively utilise the features of the console. His general familiarity with games and thus his game expertise influenced his approach and deliberations in the game context. By contrast, Claire was simultaneously developing an understanding of the game's features and game context as she played. Therefore, some of her deliberations may have been a result of her general lack of game playing as much as other factors. Although the representational motivation (Scanlon, Buckingham, \& Burn, 2005) of the game, with its strong spatial dimension, was high, distinct learning pathways for each game player followed. Claire did not go back to the game while Steve, due to his success with maps, explored further.

\section{Engagement beyond the game-playing context}

In a post game-playing interview, Steve indicated that he enjoyed navigating around the maps in the Zelda game and indicated that being able to interpret the maps was a critical component of the game. Indeed, he was generally fascinated with maps and acknowledged that this interest was present prior to playing this game and yet his interest was stimulated further after exposure to this particular game. Steve's ongoing interest in maps is highlighted in the following transcript:

Steve: We're doing a HSIE [Human Society and Its Environment] assignment at school where we've got to make an 'Amazing Race' series and we've got to say where they're going -

Interviewer: Okay.

Steve: $\quad$ So I used Google Maps to try and find some tourist places...And on Google Earth-it's a really good program because you can actually move it around to any angle you want.

Other studies have highlighted gender differences in students' game-playing engagement with boys more likely to play games with a strong dynamic component (Volman, Van Eck, Heemskerk, \& Kuiper, 2005). To some extent our case study participants matched these trends, as Claire did not identify any continued engagement with maps beyond the actual game-play situation.

Interviewer: But it did not make you want to then go and find out more about using maps?

Claire: I suppose other people would be like that, like people who are, not more so obsessive but like curious about stuff, like really curious, like they play the game and like, okay just say someone played the game and they found out about mapping and they're like, "Wow I really enjoyed the mapping, maybe I'll go and look that up". 
In addition, Steve demonstrated an ongoing desire to continue using and "playing with" maps. He enjoyed the challenge of interpreting different kinds of maps, especially after playing the Zelda game, and purposefully sought out maps in out-of-school contexts. Thus, this was an activity he undertook independently and not something he was required to do for school.

Steve: $\quad$ I really like interpreting maps. I was looking at some old photos of [town] and our suburb wasn't on here, we live just in [suburb], it wasn't on the map...

Interviewer: So just paddocks, was it?

Steve: Uh, no it was still there, like it was a 1980s map, I think. But it wasn't on the map, like they cut it off...All you could see was North [suburb] to South [suburb]. So, you couldn't see the University or anything-

Interviewer: Okay, interesting.

Steve: Um, and I thought that - at first I thought that the Uni was over up the top there [pointing] but then I saw the race course and I knew that it was back that way...But that was after I played the game, so it taught me to use a lot of map reading skills.

Although it is apparent that the game structure is an important catalyst for engaging students in challenging tasks (Williamson \& Facer, 2004), this investigation has demonstrated the applied nature of game playing into non-game situations. In this description we have highlighted the utility of digital games - not as a tool for promoting mathematics skills, but rather as a stimulus for out-of-game exploration — that provides greater depth and richness to students' learning.

\section{Conclusion}

The first phase of the study highlighted differences in the type of mathematics-based digital games males and females like to play-with males more likely to play games that require navigation and wayfinding while females enjoyed problem-solving games with cryptic mathematics challenges. In the second phase of the study we noted the different strategies and approaches of two students playing a navigational game. This game, The Legend of Zelda: Phantom Hourglass, contained challenging spatial features which needed to be interpreted and decoded and also presented the game story line through a spatial narrative. In an extensive review of the factors that determine an individual's navigational abilities, Wolbers and Hegarty (2010) proposed a model that highlighted three factors that interact to produce individual patterns of navigational performance: namely (1) spatial cues; (2) computational mechanisms; and (3) spatial representations. Of particular relevance to this study are the spatial computations and executive processes accessed within the computational mechanisms category. Successful navigators have sound spatial and self-motion perception, are able to compute directions and distances to unseen goals, can manage shifts in spatial perception, and have sophisticated novelty detection mechanisms. The two case study participants differed most markedly in this computational mechanism category as they played the game.

First, the two game players showed a desire to navigate the spatial boundaries of the game from quite distinct approaches. Steve, who was a relatively experienced game player, utilised trial-and-error approaches to navigate the game space and routinely accessed the spatial features of the games (including the dual screens) to monitor his thinking and record his wayfinding (Gerber \& Kwan, 1994). His navigational movements were frenzied and underpinned by the challenge of getting through the game quickly. His capacity to purposefully move between the screens not only heightened the experience but also become an effective tool. Steve was confident he would not get lost within the game space and appeared at ease with his dynamic movements within the game. Lin et al. (2012) argued that males tend to navigate virtual environments much faster than females - and with games like Zelda this more carefree strategizing allowed Steve to achieve success and build confidence more rapidly than Claire. By contrast, Claire was cautious with her wayfinding and tended to use more deliberate movements which took into account her understanding about where she wanted to go. This approach was less experimental than Steve's and was certainly less hazardous.

Second, there were obvious differences in the amount of "new" information the game players felt they needed to access. Specifically, Claire felt that it was necessary to read all text for fear of missing clues or strategies for moving through the game space. Her structured approach resulted in less risk taking and less 
need to navigate different pathways in order to progress through the game. On the other hand, Steve explored many more environments as he took a more investigative approach to navigating through the game space-frequently moving back and forth between screens whilst accessing information on both screens. This learning by doing approach, however, does lend itself to more experienced game players (Garris et al., 2002). Of note is a recent investigation by Meneghetti, Pazzaglia, and De Beni (2011) who found that undergraduate males were much more successful than females at solving spatial tasks that required backward mapping and referencing. In their study, these relatively complex tasks challenged participants to reproduce sequences of blocks/numbers of increasing length, in forward or reverse order. Such skills are particularly useful when navigating digital games like Zelda since there is constant, and multiple, movements forward and backward between screens.

Third, this investigation viewed game playing from a different perspective - considering the impact a particular game can have on rich learning experiences after (and away from) the game environment. To date, most studies have tended to focus on the effectiveness of games as a learning tool and not as a stimulus for out-of-game exploration. Steve may not ever play this game again; however, we have demonstrated that engagement with this game has fostered his interest in reading and interpreting maps. While Dickey (2006) reported that "narrative game scenarios provide environments in which players can gain and practice skills which may then be applied to a realworld setting" (p. 254), we are suggesting that the game triggered an awareness of real world settings that could be explored using different skills and approaches than that of the game environment.

In summary, what we have sought to illustrate in a novel way is that our players confirmed much of the research on gendered differences. The stimulated recall method allowed us to access the players' articulation of their strategies. We also confirmed the possibility that boys may engage in transference of skills and activities between contexts.

\section{Acknowledgements}

We would like to thank Lauren Carlson for her insights, support and advice on the collaboration and analysis of data for this article. The work represented in this paper was supported by an Australian Research Council (ARC) Grant [DP0987253]. The views and ideas drawn from the research are that of the authors and not the ARC.

\section{References}

Amory, A., Naicker, K., Vincent, J., \& Adams, C. (1999). The use of computer games as an educational tool: Identification of appropriate game types and game elements. British Journal of Educational Technology, 30(4), 311-321.

Anzai, Y., \& Simon, H. (1979). The theory of learning by doing. Psychological review, 86(2), 124-140.

Betz, J. A. (1996). Computer games: Increase learning in an interactive multidisciplinary environment. Journal of Educational Technology Systems, 24(2), 195-205.

Boardman, D. (1990). Graphicacy revisited: Mapping abilities and gender differences. Educational Review, 42, 57-64.

British Educational Technologies and Communications Agency (BECTA). (2002). Young people's use of ICT questionnaire. Retrieved from http://www.becta.org.uk/youngpeopleict/

Buckingham, D. (2007). Beyond technology: Children's learning in the age of digital culture. Cambridge: Polity Press.

Charsky, D. (2010). From edutainment to serious games: A change in the use of game characteristics. Games and Culture, 5(2), 177-198. 
de Kort, Y. A. W., Ijsselsteijn, W. A., \& Gajadhar, B. J. (2007). People, places, and play: A research framework for digital game experience in a socio-spatial context. In Situated play: Proceedings of the Digital Games Research Association (DiGRA) conference (pp. 823-830). Tokyo: DiGRA.

Dickey, M. D. (2006). Game design narrative for learning: Appropriating adventure game design narrative devices and techniques for the design of interactive learning environments. Educational Technology Research and Development, 54(3), 245-263.

Diezmann, C. M., \& Lowrie, T. (2008). Assessing primary students' knowledge of maps. In O. Figueras, J. L. Cortina, S. Alatorre, T. Rojano, \& A. Sepúlveda, (Eds.), Proceedings of the 31st annual conference of the International Group for the Psychology of Mathematics Education and the North American Chapter (Vol. 2, pp. 415-421). Morealia, Michoacán, México: PME.

Feng, J., Spence, I., \& Pratt, J. (2007). Playing an action video game reduces gender differences in spatial cognition. Psychological Science, 18(10), 850-855.

Garris, R., Ahlers, R., \& Driskell, J. E. (2002). Games, motivation and learning: A research and practice model. Simulation and Gaming, 33(4), 441-467.

Gass, S., \& Mackey, A. (2000). Stimulated recall methodology in second language research. Mahwah, NJ: Lawrence Erlbaum.

Gee, J. P. (2007). What video games have to teach us about learning and literacy (Rev. ed.). Basingstoke: Palgrave Macmillan.

Gerber, R., \& Kwan, T. (1994). A phenomenographical approach to the study of pre-adolescents' use of maps in a wayfinding exercise in a suburban environment. Journal of Environmental Psychology, 14, $265-280$.

Hartmann, T., \& Klimmt, C. (2006). Gender and computer games: Exploring females dislikes. Journal of Computer-Mediated Communication, 11(4), 910-931.

Hegarty, M., Montello, D. R., Richardson, A. E., Ishikawa, T., \& Lovelace, K. (2006). Spatial abilities at different scales: Individual differences in aptitude-test performance and spatial-layout learning. Intelligence, 34, 151-176.

Henderson, L., Klemes, J., \& Eshet, Y. (2000). Just playing a game? Educational simulation software and cognitive outcomes. Journal of Educational Computing Research, 22(1), 105-129.

Henderson, L., \& Tallman, J. (2006). Stimulated recall and mental models: Tools for teaching and learning computer information literacy. Lanham, Maryland: Scarecrow Press, Rowman \& Littlefield Publishing Group Inc.

Jorgensen, R., \& Lowrie, T. (2011). Digital games: Creating new opportunities for mathematics learning. In J. Clark, B. Kissane, J. Mousley, T. Spencer, \& S. Thornton (Eds.), Mathematics: Traditions and [new] practices: Proceedings of the 34th annual conference of the Mathematics Education Research Group of Australasia and the Australian Association of Mathematics Teachers (pp. 406-413). Alice Springs, Australia: AAMT and MERGA.

Kimchi, R., Amishav, R., \& Sulitzeanu-Kenan, A. (2009). Gender differences in global-local perception? Evidence from orientation and shape judgments. Acta Psychologica, 130(1), 64-71.

Kitchin, R. (1996). Are there sex differences in geographic knowledge and understanding? The Geographical Journal, 162, 273-286.

Lawton, C. A. (1994). Gender differences in way-finding strategies: Relationships to spatial ability and spatial anxiety. Sex Roles, 30(11/12), 765-779. 
Lawton, C. A., \& Kallai, J. (2002). Gender differences in wayfinding strategies and anxiety about wayfinding: A cross-cultural comparison. Sex Roles, 47(9/10), 389-401.

Lin, C-T., Huang, T-Y., Lin, W-J., Chang, S-Y., Lin, Y-H., Ko, L-W., Hung, D. L., \& Chang, E. C. (2012). Gender differences in wayfinding in virtual environments with global or local landmarks. Journal of Environmental Psychology, 32(2), 89-96.

Lowrie, T. (2002). The influence of visual and spatial reasoning in interpreting simulated 3D worlds. International Journal of Computers for Mathematical Learning, 7, 301-318.

Lowrie, T., \& Diezmann, C. M. (2007). Solving graphics problems: Student performance in the junior grades. Journal of Educational Research, 100(6), 369-377.

Lowrie, T., \& Diezmann, C. M. (2009). National numeracy tests: A graphic tells a thousand words. Australian Journal of Education, 53(2), 141-158.

Lowrie, T., \& Diezmann, C. M. (2011). Solving graphics tasks: Gender differences in middle-school students. Learning and Instruction, 21(1), 109-125.

Lowrie, T., \& Jorgensen. R. (2011). Gender differences in students' mathematics game playing. Computers and Education, 57(4), 2244-2248.

Lucas, K., \& Sherry, J. L. (2004). Sex differences in video game play: A communication-based explanation. Communication Research, 31, 499-523.

Meneghetti, C., Pazzaglia, F., \& De Beni, R. (2011). Spatial mental representations derived from survey and route descriptions: When individuals prefer extrinsic frame of reference. Learning and Individual Differences, 21, 150-157.

Miller, D., \& Robertson, D. (2010). Using a games console in the primary classroom: Effects of "Brain Training" programme on computation and self esteem. British Journal of Educational Technology, 41(2), 242-255.

Morgan, A. (2007). Using video-stimulated recall to understand young children's perceptions of learning in classroom settings. European Early Childhood Education Research Journal, 15(2), 213-226.

Morse, J. M. (2003). Principles of mixed methods and multimethod research design. In A. Tashakkori \& C. Teddlie (Eds.), Handbook of mixed methods in social and behavioural research (pp. 189-208). Thousand Oaks, CA: Sage Publications.

Nemirovsky, R., \& Noble, T. (1997). Mathematical visualization and the place where we live. Educational Studies of Mathematics, 33(2), 99-131.

Nintendo. (2008). The Legend of Zelda: Phantom Hourglass [Video game]. Nintendo.

Presmeg, N. C. (1986). Visualisation in high school mathematics. For the Learning of Mathematics, 6(3), 42-46.

Quaiser-Pohl, C., Geiser, C., \& Lehmann, W. (2006). The relationship between computer-game preference, gender, and mental-rotation ability. Personality and Individual Differences, 40(3), 609619.

Rice, J. W. (2007). Assessing higher order thinking in video games. Journal of Technology and Teacher Education, 15(1), 87-100.

Rieber, L. P., Smith, L., \& Noah, D. (1998). The value of serious play. Educational Technology, 38(6), 29-37. 
Sandford, R., Ulicsak, M., Facer, K. \& Rudd, T. (2006). Teaching with games: Using commercial off-theshelf computer games in formal education. Futurelab. Retrieved from

http://www.futurelab.org.uk/projects/teaching_with_games/research/final_report

Sandstrom, N. J., Kaufman, J., \& Huettel, S. A. (1998). Males and females use different distal cues in a virtual environment navigation task. Cognitive Brain Research, 6, 351-360.

Saucier, D. M., Green, S. M., Leason, J., MacFadden, A., Bell, S., \& Elias, L. J. (2002). Are sex differences in navigation caused by sexually dimorphic strategies or by differences in the ability to use the strategies? Behavioral Neuroscience, 116(3), 403-410.

Scanlon, M., Buckingham, D., \& Burn, A. (2005). Motivating maths? Digital games and mathematical learning. Technology, Pedagogy and Education, 14(1), 127-139.

Shin, N., Norris, C., \& Soloway, E. (2006). Effects of handheld games on students learning in mathematics. Proceedings of the 7th International conference on Learning Sciences. Bloomington, Indiana: International Society of the Learning Sciences.

Sims, V., \& Mayer, R. (2002). Domain specificity of spatial expertise: The case of video game players. Applied Cognitive Psychology, 16, 95-115.

Stake, R. E. (1995). The art of case study research. Thousand Oaks: Sage Publications.

Studiocode Business Group. (2003). Studiocode (Version 3) [CD]. Sydney: Sportstec Limited.

Thorndyke, P. W. (1982). Differences in spatial knowledge acquired from maps and navigation. Cognitive Psychology, 14(4), 560-589.

Van Eck, R. (2006). Digital game-based learning: It's not just the digital natives who are restless. EDUCAUSE Review, 41(2), 16-18.

Volman, M., Van Eck, E., Heemskerk, I., \& Kuiper, E. (2005). New technologies, new differences. Gender and ethnic differences in pupils' use of ICT in primary and secondary education. Computers \& Education, 45(1), 35-55.

Wenglinsky, H. (1998). Does it compute? The relationship between educational technology and student achievement in mathematics. Princeton, NJ: Educational Testing Service.

Wien, C., \& Darling-Hammond, L. (1998). Limited vision: The Ontario curriculum and outcomes-based learning. Canadian Journal of Education, 23(4), 405-420.

Williamson, B., \& Facer, K. (2004). More than 'just a game': The implications for schools of children's computer game communities. Education, Communication and Information, 4(2/3), 255-270.

Wolbers, T., \& Hegarty, M. (2010). What determines our navigational abilities? Trends in Cognitive Sciences, 14(3), 138-146.

Zevenbergen, R. (2007). Digital Natives come to preschool: Implications for early childhood practice. Contemporary Issues in Early Childhood, 18(1), 19-29.

Corresponding author Tom Lowrie, tlowrie@csu.edu.au

Australasian Journal of Educational Technology (C) 2013.

Please cite as: Lowrie, T., Jorgensen, R., \& Logan, T. (2013). Navigating and decoding dynamic maps: Gender preferences and engagement differences within- and outside-of game experiences. Australasian Journal of Educational Technology, 29(5), 626-639. 